\title{
Incremental Role of Family Relationships and Hurt Intensity in Forgiveness of Family Offenders: A Study of College Students in Taiwan
}

\author{
Inna Reddy Edara1, Jo-Lin Chen ${ }^{2 *}$ \\ ${ }^{1}$ Graduate Institute of Educational Leadership \& Development, Fu Jen Catholic University, Taiwan \\ ${ }^{2}$ Department of Child \& Family Studies, Fu Jen Catholic University, Taiwan \\ Email: 065049@mail.fju.edu.tw, *046286@mail.fju.edu.tw
}

How to cite this paper: Edara, I. R., \& Chen, J.-L. (2018). Incremental Role of Family Relationships and Hurt Intensity in Forgiveness of Family Offenders: A Study of College Students in Taiwan. Psychology, 9, 1023-1049.

https://doi.org/10.4236/psych.2018.95065

Received: March 29, 2018

Accepted: May 18, 2018

Published: May 22, 2018

Copyright (๑) 2018 by authors and Scientific Research Publishing Inc. This work is licensed under the Creative Commons Attribution International License (CC BY 4.0).

http://creativecommons.org/licenses/by/4.0/

(c) (i) Open Access

\begin{abstract}
This quantitative research investigated the determinants of forgiveness of a family transgressor by the offended. Data from 377 college students were analyzed to investigate the nature and frequency of the offenses, specific relationship of the offended with the transgressor, and the role of family relationship variables, positive dispositional tendencies, and hurt intensity in the forgiveness of the family member. The analyses indicated that some of the most occurring offenses were being ignored, not fulfilling promises, and being compared with others. Participants indicated being compared with others as the most serious offense, followed by contempt, and being ignored. Due to these offenses, about $50 \%$ of the participants experienced moderate to above the average intensity of hurt. Hierarchical multiple regression analyses suggested that the positive dispositional tendencies of optimism alone explained $16 \%$ of incremental variance in forgiveness after controlling for gender. Resilience was not significant. In the third step of the regression, family relationship variables of trust, communication, and alienation together explained an additional $37 \%$ of the variance, above and beyond gender and dispositional tendencies. In the final step, hurt intensity was a significant predictor, explaining an additional 5\% of variance in forgiveness. These significant results suggest that after controlling for both demographic variables and dispositional traits, the family relationship variables along with the subjective hurt intensity in the context of a family play a significant role in the forgiveness of the family offender.
\end{abstract}

\section{Keywords}

Forgiveness, Hurt, Offense, Trust, Communication, Alienation, Resilience, Optimism 


\section{Introduction}

Although there has been a great increase in focus on the construct of individual forgiveness in the psychological and social sciences research over the last 25 to 30 years, only recently the researchers have been paying attention to understanding of the ways in which forgiveness is operational in the context of family offenses and the well-being of individuals within the families. Because of the important role of family relationships in the quality of life of family members (Beach \& Whisman, 2012), many needs of the individuals are usually fulfilled in families, while some of the strongest offenses and deepest hurts also occur in family relationships (Fincham, 2015).

In other words, on the one hand, family life can be full of joy and happiness, but on the other hand, hurt and pain are inflicted and received even in the healthiest of families. Those families that do not find ways to minimize pain and maximize forgiveness may realize that hurts do not heal as easily and the consequential residuals carry over throughout a lifetime (DeBlasio, 1998). Therefore, working toward forgiveness in families is very important, for without it, the consequences are detrimental to both the family and individual well-being. In the following pages, we provide a brief description of the summary of literature review, including the description of the relationships in families in general and in Taiwanese context in particular, common offenses occurring in families, and some relatively important determinants of forgiveness in the context of family transgressions.

\section{Literature Review}

\subsection{Family Relationships in Confucian Philosophy and Taiwanese Culture}

Confucianism, developed by the greatest Chinese philosopher, Confucius, is a philosophy which focuses on a complex set of ethical and moral rules that dictate how people relate to others in the conduct and practices of their daily lives (Huang \& Gove, 2012). For example, in Confucianism, there are five cardinal virtues that one has to pursue (Park \& Chesla, 2007): benevolence (ren), righteousness $(y i)$, rite $(l i)$, understanding (zhi), and trust (xin).

The Chinese character ren represents the figure of two people, indicating that ren is thought to be possible only when one human being is in relationship with another and thus one cannot be ren by oneself. The cultivation of ren starts from one's own home and family. Love of one's parents is the first quality of ren, followed by the love for one's siblings. Thus, ren starts from very specific and close relationships in the family. Similarly, the notion of $y i$ is that when one acts, the intention should be righteous in relationships. Therefore, yi and ren are considered as the most important basic virtues of early Confucianism. $L i$ is defined as the boundaries of proper behavior that provide opportunities for satisfying desires of moral agents. As ren is possible only in relation to other people, $l i$ is possible only in the context of relationships and social structures (Park \& Chesla, 
2007). Zhi refers not to the "knowing about" but rather to the ability to recognize and differentiate between good and "not-good." The Chinese character of xin refers to trust and is interpreted as the state of mind that is without deception when relating to others. In one's family and social life, if one is to have a meaningful relationship with others, one should be trustworthy (Zhang, 2002).

Based on the basic virtues, Confucianism endorses five basic relationships for humans through which each person defines a sense of identity, duty, and responsibility. They are: ruler-subject, father-son or parents-children, husband-wife, elder-younger or between siblings, and between friends (Park \& Chesla, 2007). Confucianism endorses closeness between parents and children. In all familial relations, respect for parents and grandparents has a supreme value. However, the guidance and discipline that parents give to their children is also important, and it should be based on emotional closeness and love. The elders are supposed to treat the younger generation with affection, and they are allowed to be strict but not cruel. Between siblings, older siblings are expected to be a role model for their younger siblings, and in turn, younger ones are to respect the older ones. The oldest among siblings usually acts as the surrogate of parents in their absence.

Therefore, three out of five of these relations occur in the family (Chang \& Holt, 1991), confirming a strong representation of the notion that family is the base of society (Park \& Chesla, 2007). Chinese cultures advocate that one should strive to expand the prosperity and vitality of one's family to the larger society (Huang \& Gove, 2012). Thus, the ideal social relationship is the one that demonstrates qualities that parallel those found in family life. Conversely, a person who does not do well within family relationships cannot do well in society (Park \& Chesla, 2007). To cultivate and maintain harmony within the context of family, it often takes into consideration parent's authority, conformity, and role and responsibilities of each individual ( $\mathrm{Lu} \&$ Shih, 1997). The strong affection that parents have toward their children drives them to be highly attentive to the well-being of their dependent child, while the decisions children make regarding their lives, including education, are associated with family harmony as well. Thus, for Confucians, it follows that as one grows up, one ought to reciprocate the good by being a filial child.

Filial piety (xiao-shun), therefore, entails not only provision of material goods, but also serving one's parents with a caring mind and reverent attitude. Yet, it is also important to be aware of the rather common misconstrued understanding of filial piety as requiring absolute obedience and submission to their parents. Instead, one should follow what is morally right. In other words, if parents require children to do wrong, a filial child not only should reject it, but even has an obligation to correct the parents in a tactful way (Nuyen, 2004). It is with this proper understanding that filial piety is regarded as the root of the cardinal and all-encompassing Confucian virtue of ren, which is also often referred as a moral force that comes with one's ability to show benevolence and kindness toward others (see Chan, 1963). In addition, it is important to note that although family 
plays a significant role in its members' personal welfare, the value of family is not merely instrumental, because family is not a joint venture set up by voluntary individuals but a social reality that everyone is born into for better or worse (Brennan \& Fan, 2007). Confucian philosophy also holds that assuming the familial roles and responsibilities properly is central to cultivation and practice of virtues; this does not entail ignoring the interests of each member, but rather accommodates values that will serve the best interest of the family and the members (Fan, 2002).

In Taiwanese context, families are typically multigenerational, with each member playing an important function within the household. Traditionally, the Taiwanese placed great emphasis on maintaining respect and positive relationships among the family members. Much of this behavior relates back to Confucian concept of filial piety (xiao-shun). Taiwanese also emphasize relationships (guan-xi), which means being reciprocal towards one's obligations to family members. The concept of face-saving (mian-zi) in Taiwanese families often guides how family members interact with one another and with others. As the younger generation is becoming less family orientated, Confucian concepts are not strictly followed anymore. Nevertheless, children in Taiwan are still expected to obey and defer to their parents and honor their elders in almost all the situations (Family, 2017).

As a summary, we can say that in general, including in the context of families in Taiwan, family relationships are the most valued aspect of any person's life. On the one hand, family plays a crucial role in the well-being of its members, and on the other, family has been found to be the greatest cause of emotional stress and problem behaviors (Cavanagh \& Huston, 2008). Battle and Miller (2005) said that because family relationships usually involve longer term and more intimate affiliations, there are more possibilities for interpersonal transgressions to occur more often in the family relationships than in other relationships. Conflicts that cause hurts in family relationships may be occasioned by a violation of an implicit or explicit relationships norm (Confucian values of ren and $l i$, and the cultural value of guan-xi), intentional or unintentional deceit and betrayal of trust (Confucian values of $y i$ and $x i n$ ), and so on (Karremans, Van Lange, Ouwerkerk, \& Kluwer, 2003; Rusbult \& Van Lange, 2003).

Battle and Miller (2005) suggested that a wide range of transgressions necessitate forgiveness in families, including unequal treatment of siblings by one or both parents, hurt feelings from divorce and/or remarriage, irresponsible financial decisions made by a family member, inequitable distribution of household tasks, and repeated instances of broken family commitments. Hoyt, Fincham, McCullough, Maio, and Davila (2005) refer to the precipitating causes of these feelings of hurt and resentment, and attendant cognitions as interpersonal transgressions.

\subsection{Theories of Interpersonal Transgressions}

Hoyt et al. (2005) suggest that when researchers study interpersonal transgres- 
sions in close relationships, they should factor in the role of the situational and relational factors that would contribute to people's willingness to forgive, over and above their stable dispositional tendencies. Some of the theories that explain the role of the situational and relational factors in interpersonal transgression and family forgiveness are interpersonal theory, interdependence theory, transactional theory, and social relations model.

Interpersonal theory suggests that the principle of complementarity influences interaction dynamics (Markey, Funder, \& Ozer, 2003), and not only recent but also remote past behaviors encoded in the form of ongoing expectations influence a person's present responses to that partner in their interpersonal interactions (Fincham, Harold, \& Gano-Phillips, 2000). Interdependence theory posits that dyadic interaction behaviors are a function of the situation and of the needs, thoughts, and motives of the two interactants (Finkel, Rusbult, Kumashiro, Hannon, 2002; Rusbult \& Van Lange, 2003). Transactional perspective endorses that specific transgressions in close relationships occur within the context of an ongoing stream of interaction, with members sometimes playing the role of an offender and other times the role of a victim (Cotterell, Eisenberger, \& Speicher, 1992).

In social relations model, the idea that dyadic interpersonal phenomena are necessarily componential, consisting of transgressor (actor or perceiver), victim (partner or target), and relationship components (Back \& Kenny, 2010). Based on these theoretical frameworks, scholars indicate that the extent to which people forgive in families is influenced not only by the dispositional characteristics of the forgiver, but also by the relationship, the situation in which the transgression occurs, the characteristics of the transgressor and the nature of the offense (see McCullough, Fincham, \& Tsang, 2003; Mullet \& Girard, 2000; Takaku, Weiner, \& Ohbuchi, 2001; Wieselquist, Rusbult, Foster, \& Agnew, 1999). In other words, the victims are primarily motivated to forgive the transgressor in order to continue or restore the relationship (Karremans \& Van Lange, 2004; Mooney, Strelan, \& McKee, 2015).

\subsection{Concepts of Forgiveness}

In the light of the theories of interpersonal transgressions, forgiveness is described as an intentional and voluntary process that involves a change in emotion and attitude in a victim regarding an offender (see Fincham, 2000; Kaminer, Stein, Mbanga, \& Zungu-Dirwayi, 2000; McCullough, Worthington, \& Rachael, 1997; North, 1987; Worthington, 2005). Scholars conceptualize forgiveness on the basis of two inter-related processes. One is intrapersonal, in which the cognitions and feelings of victims about a transgressor change from negative to positive (Worthington, 2001). The other is interpersonal (Finkel et al., 2002), in which the internal prosocial motivational change experienced by victims is manifested interpersonally. Therefore, a feature of the interpersonal aspect of forgiveness is that it involves positive responses to transgressors, variously concep- 
tualized as benevolent (McCullough et al., 1998), compassionate and loving (Worthington, 2001), and altruistic (Enright, Freedman, \& Rique, 1998). Hence, regardless of the nomenclature, a forgiving response at the interpersonal level implies other-focused concern (Mooney et al., 2015).

Scholars also conceptualize forgiveness at different levels of specificity, such as a trait, as a tendency toward a specific relationship, and as a response toward a specific offense (see Fincham, Hall, \& Beach, 2006; McCullough, Hoyt, \& Rachal, 2000). Paleari, Regalia, and Fincham (2009) indicated that both positive and negative dimensions of forgiveness were more strongly related to the relationship (tendency and response) variables than to the trait variables, suggesting that the relational characteristics may be more important than the dispositional traits in understanding forgiveness. In addition, relationship characteristics (ex., closeness, trust, and conflict) are widely accepted as playing a significant role in forgiveness in the family contexts (see Fincham, 2015; Hoyt, Fincham, McCullough, Maio, \& Davila, 2005; Maio, Thomas, Fincham, \& Carnelley, 2008; Paleari, Fincham, \& Regalia, 2003).

After reviewing the literature on the concept of forgiveness in Confucianism, Shun (2014) concluded that the concept of forgiveness is neither developed nor idealized in Confucian thought. Shun said that in contemporary Chinese language, there are several expressions, such as yuan-liang, kuan-shu, rao-shu, kuan-rong, and she-mian, which are standardly used as translations of the term "forgive" or "forgiving." Shun said that there are no indications in the classical Chinese texts in the sense in which the compound yuan liang is used in modern Chinese language. As for $s h u$, it is explained in terms of not bestowing ( $s h i$ ) on others what one would not desire to be bestowed on oneself. Thus, shu is usually presented as a desirable quality, presumably referring to one's being considerate in bestowing things on and in dealing with others, rather than referring specifically to a "forgiving" attitude toward an offender. In addition, in contemporary Chinese language, shu is in the compound kuan-shu as a possible translation of "to forgive," and kuan is also viewed generally as a desirable quality in the early texts, referring to a mindset that is being broad-minded (kuan) in contrast to being narrow-minded $(b i)$. Kuan is also used in modern Chinese language in the compound kuan-rong to describe one's being broad-minded, encompassing and accommodating. Finally, in many instances of its use, she involves one's refraining from punishing someone for a crime or an offence that is punishable by some established standards. In a similar way, mian often refers to one's avoiding some disastrous outcomes. Hence, she-mian is also not like the contemporary notion of forgiveness.

Thus, Shun's (2014) examination of the early use of Chinese terms potentially related to the notion of forgiveness shows that these terms either have to do primarily with actions, or if they have to do with the mindset or disposition, a change conveyed through their use is primarily a matter of correcting some aspect in the victim, such as a change from being narrow-minded (bi) to being 
broad-minded (kuan). This is unlike the kind of change of mind or heart involved in the contemporary notion of forgiveness, which emphasizes a change in the way one views an offender. Therefore, the question is, in what way is this kind of change different from that involved in the contemporary discussions of forgiveness? In contemporary understanding of forgiveness, the victim abandons the attitudes associated with resentment, drops any presumption of one's own importance or moral superiority, empathetically sees things from the perspective of the offender, and comes to view the offender as someone with whom one can maintain a relationship. On the other hand, the change in the Confucian view involves the victim correcting some aspect in oneself, and it is a change that the victim should undertake independently of any change on the part of the offender. Thus, by downplaying the importance of the way others view oneself and by no longer seeing acts of offense as attacks on one's self-respect, the victim's initial resentment dissipates, and the victim perhaps comes to see the offender in the same way that would have resulted from an act of forgiveness, namely, the offender is someone with whom the victim can restore a relationship.

\subsection{Hurt Intensity and Forgiveness}

Although family life is a source of joy and happiness, it is a rare phenomenon that a person who does not, at some point, feel hurt when let down, betrayed, disappointed or wronged by a close family member. When a person is offended by a family member, he or she can experience strong negative feelings, which in turn, can elicit the severity of the hurt. Also, how the offended respond to transgressions in family context depends on the intensity of hurt, which in turn may affect the way in which the offended behave toward the offender in the future interactions. McCullough, Worthington, and Rachal (1997) posited that the affective responses in family transgressions occur along two dimensions: one reflects emotions (e.g., sadness, anger, and contempt) related to righteous indignation, whereas the other dimension captures emotions ((e.g., fear and worry) related to hurt.

Wade and Worthington (2003) reviewed several studies that used several variables in predicting the degree of forgiveness or unforgiveness that a victim would experience in response to a hurt. Dispositional traits, such as religiosity, empathy, and agreeableness were related to willingness to forgive interpersonal transgressions across situations. Trait anger, proneness to shame, attachment style, quality of the relationship, and the severity of the offence were considered influential in the process of unforgiveness. For instance, a transgression that was more severe was indicated to produce more feelings of unforgiveness, which would make it more difficult for the victim to forgive the offender, than was a relatively minor offence and less severe hurt.

Boon and Sulsky (1997) reported that the severity of partner transgressions was linked to partner forgiveness with more severe transgressions being associated with less forgiveness. A study by Fincham, Jackson, and Beach (2005) 
suggested that the participant's rating of the transgression severity or hurt intensity significantly predicted forgiveness. The significant negative correlation between subjective hurt severity and forgiveness in Fincham et al.'s study indicated that those who subjectively perceived higher levels of hurt intensity were less inclined to forgive their offenders, thus proving that subjective severity of transgression is significantly consequential for forgiveness. In other words, the more severe the subjective impact of the hurt, the harder it was for the victim to forgive the offender.

\subsection{Dispositional Traits and Forgiveness}

Research on forgiveness and personality has consistently indicated a significant relationship between them. For instance, the personality trait of extraversion and agreeableness have consistently and positively correlated with forgiveness, whereas neuroticism negatively correlated (Brose, Rye, Lutz-Zois, \& Ross, 2005). Symington, Walker, and Gorsuch (2002) stated that personality dispositions play a significant role in the study of situational forgiveness, and they indicated that neuroticism and agreeableness were significantly associated with various dimensions of forgiveness.

With the emergence of positive psychology, the traits of resilience and optimism have been considered as the personality dispositions that significantly contribute to the outcome variables. Resiliency is an internal disposition that people use to master the periods of disruption and reintegration throughout the life cycle (Flach, 1988). Optimism is a dispositional trait that reflects the extent to which individuals hold generalized favorable future expectancies in the midst of unfavorable situations (Walsh, 2003).

When the researchers attempt to study the interpersonal transgressions and forgiveness in close relationships, Hoyt and colleagues (2005) suggested to partial out the variance contributed by the stable personality and dispositional tendencies of the offended, so that the incremental validity of the role of the situational and relational variables in forgiveness of the offenders could be appropriately assessed. In this study, the variance accounted for by the positive dispositional traits of resilience and optimism were controlled for in order to validly assess the incremental variance of the relationship variables and hurt intensity in family forgiveness.

\section{Research Hypotheses}

From the literature review, it is obvious that although it is in the family relationships that many needs of the individuals are fulfilled, yet some of the strongest offenses and deepest hurts also occur in them. If families do not attempt to find ways to minimize pain and maximize forgiveness, consequently they may realize that hurts do not heal as easily and the residuals carry over throughout a lifetime. In contrast to the majority of social relationships, family relationships usually involve affiliation that lasts longer term and are more inti- 
mate. Because of the everyday nature of family relations and interactions that create the intense emotional involvement and the interdependence among the various family members, there tends to be higher possibilities for interpersonal transgressions to occur more often in the family relationships than in other relationships. Consequently, the stakes are higher when such hurts remain unresolved. Therefore, working toward forgiveness in families is very important, for without it, the consequences are detrimental to the well-being of both the family and an individual. Also, as the literature review has indicated, the relational characteristics may be more important than dispositional traits in conceptualizing, measuring, and understanding forgiveness in the context of interpersonal transgressions in family relationships.

Hence, in line with the rationale of the existing literature, we specifically investigated the role of dispositional, family relational, and hurt intensity variables in the offense-specific family forgiveness from the perspective of college students in Taiwan. We used the incremental validity paradigm, which refers to the degree to which a variable is said to significantly predict important outcome after the variance of the established variables, such as personality traits, has been removed from the predictive equation (Sechrest, 1963). Incremental validity paradigm simply answers the question of whether a variable adds to the prediction of the criterion over and above that can be predicted by other established variables (Haynes \& Lench, 2003).

Specific research hypotheses included:

1) Exploration of the a) specific family member committing the offense, b) nature and frequency of the offenses committed by this specific offender, and the single most serious offense, and c) the level of hurt intensity.

2) Investigation of the significant correlations between the major study variables. For example, a positive correlation would be expected between the dispositional tendencies of optimism and resilience, family relationship variables of trust and communication, and forgiveness. A negative correlation would be expected between the family relationship variable of alienation, hurt intensity, and forgiveness.

3) Investigation of the incremental effect of the family relationship and hurt intensity variables on family forgiveness. That is, after controlling for significant demographics, it would be expected that the positive dispositional tendencies, family relationship variables, and hurt intensity would significantly predict the offense-specific forgiveness. Specifically, positive tendencies and relationship variables of trust and communication in their respective regression analysis steps would predict an increase in forgiveness, whereas the family relationship variable of alienation and hurt intensity in their respective regression analysis steps would predict a decrease in forgiveness.

\section{Method}

\subsection{Procedure and Participants}

After obtaining the consent of the voluntary participants, we collected data from 
377 undergraduate students pursuing a bachelor degree in different areas of study at a certain large comprehensive university in Taiwan. In general, the students belonged to various colleges and departments, including those majoring in child and family studies, education, leadership, clinical psychology, English literature, engineering, nursing, management, psychology, Chinese literature, and continuing education. Before proceeding with answering the questions, the voluntary participants were invited to acknowledge the consent form, which indicated their willingness to participate in the survey, the purpose of the survey, and the time it would take to complete the survey questionnaire. The participants were also told that they were free to quit the survey any time in the process. No compensation was given for their participation.

The total sample of 377 participants consisted of $160(42.4 \%)$ males and 217 (57.6\%) females. Their ages included between 18 and $25(18=27 ; 19=117 ; 20=$ $113 ; 21=52 ; 22=38 ; 23=18 ; 24=8 ; 25=4)$. The majority $(134 ; 35.5 \%)$ had no religious belief. Of those who were affiliated with some religion, 73 (19.4\%) participants were affiliated with some sort of folk religions; 67 (17.8\%) were Taoists; 55 (14.6\%) were Buddhists; 40 (10.6\%) were Protestants, and 8 (2.1\%) were Catholics.

\subsection{Measurements}

Demographic, Offense-Descriptive, and Hurt Intensity Questionnaire. The participants' demographic information, including age, gender, college and the major they are enrolled in, and religious affiliation were collected. We also asked the participants to choose one of the close family members (father, mother, and sibling) that they perceive to have seriously offended them in the recent past. Then, we requested the participants to choose any number of offenses from a random list of 29 offenses that the chosen family offender had committed against them. The sample offenses included being ignored, verbal abuse, dishonesty, failing in commitments, conflict with the use of resources, conflicts with parental discipline, conflicts in the distribution of household tasks, interpersonal relationship conflicts, and others. We then asked the participants to indicate the most serious offense from their chosen list of offenses and the hurt intensity ranging from zero to 10, with zero representing no hurt feelings, 5 representing medium intensity of hurt, and 10 representing the most intense hurt.

Offense-Specific Family Forgiveness. In assessing offense-specific family forgiveness, we modified and used 15 items from the Forgiveness Scale (Rye, Loiacono, Folck, Olszewski, Heim, \& Madia, 2001). Responses were made on a 5-point Likert scale ranging from 1 (strongly disagree) to 5 (strongly agree). We subjected the 15 items to principal component analysis, which revealed the presence of two components, explaining $60.38 \%$ of the variance. The first component, which we named as Absence of Negative, had 8 items with factor loadings ranging from .58 to .83 , explained $31.21 \%$ of variance and had a Cronbach's $\alpha$ of .91. The second component, named as Presence of Positive, had 7 items 
with loadings from .62 to .75 , explained $29.17 \%$ of variance, and had a Cronbach's $\alpha$ of .84. A sample item in the Absence of Negative included "I feel hatred whenever I think about the family member who hurt me" and a sample item in the Presence of Positive included, "Although my family member hurt me, I definitely put what happened aside so that we could resume our relationship." We reverse scored all the items in the Absence of Negative component and tabulated the total forgiveness score from both the components, which had a Cronbach's $\alpha$ of .90 .

Family Relationship. We assessed family relationship by using the Inventory of Parent Attachment developed by Armsden and Greenberg (1987). For the purpose of this study and as it was already done in the past (see Yang \& Chen, 2016), we changed "relationship with the parents" to "relationship with the family member." This inventory has three subscales: Trust, Communication, and Alienation, each consisting of five items. We did the factor analysis on all the items and as in the original scale, three clear components emerged, explaining $74.79 \%$ of the variance. The first component, Communication, had loadings in the range of .70 to .82 , explained $30.60 \%$ of variance, and had a Cronbach's $\alpha$ of .92. Sample items included, "When we discuss things, my family member cares about my point of view" and "My family member helps me to understand myself better." The second component, Alienation, had loadings in the range of .72 to .81 , explained $22.62 \%$ of variance, and had a Cronbach's $\alpha$ of .87. Sample items included, "Talking over my problems with my family member makes me feel ashamed or foolish" and "I get upset easily around my family member." The third component, Trust, had loadings in the range of .40 to .82, explained $21.57 \%$ of variance, and had a Cronbach's $\alpha$ of .93. Sample items included, "My family member trusts my judgment" and "I trust my family member."

Positive Dispositional Tendencies. Selected positive dispositional tendencies included Optimism and Resilience. Measure of Optimism consisted of 4 items and had reliability coefficient of .84. Sample items included, "In uncertain times, I usually expect the best" and "I always look on the bright side of things" (Carifio \& Rhode, 2002). Measure of Resilience consisted of 4 items, and the reliability coefficient of .84 . Sample items included, "I usually take stressful things in stride" and "I can achieve goals despite obstacles" (Campbell-Sills \& Stein, 2007).

\section{Results}

\subsection{Offending Family Member, Nature and Frequency of Offenses, and Hurt Intensity}

As part of Hypothesis 1a, we explored the relationship of the research participant with the offending family member. In this research, we presumed the participants' family to be exclusive and nuclear, consisting of father, mother, and siblings. The results suggested that $127(33.7 \%)$ chose their father as the offender, $122(32.4 \%)$ chose their mother, and 128 (34\%) chose a sibling. 
In Hypothesis $1 \mathrm{~b}$, we explored the nature of the offensive attitudes and behaviors that commonly occur in the families, and the single most serious offense among all the offenses that the participants perceived it to be. Some of the most often occurring offenses included the behavior or attitude of being ignored by the family members, breaking promises, being compared with others, inequitable distribution of household tasks, contempt, conflict in the use of resources and management of money, and the unequal parental treatment of the siblings. When we asked the participants to choose the most serious offense, they chose being compared with others by the offending family member $(n=37 ; 9.8 \%)$, followed by contempt $(n=30 ; 8 \%)$, family members not fulfilling their promises $(n=27 ; 7.2 \%)$, being ignored $(n=25 ; 6.6 \%)$, and verbal abuse $(n=22 ; 5.8 \%)$.

In Hypothesis 1c, we examined the level of hurt intensity. We asked the participants to choose the hurt intensity by marking between zero and ten on a continuous scale, with zero indicating absence of any sort of hurt feelings, 5 indicating the moderate intensity and 10 indicating the highest intensity of hurt. The results are presented in Table 1 . About 176 participants experienced the moderate levels of intensity ( (level $=5 ; n=61 ; 16.2 \%$; level $=6 ; n=64 ; 17 \%$, and level $=7 ; n=51 ; 13.5 \%)$. Seven $(1.9 \%)$ participants even experienced the strongest intensity of hurt due to the offensive behavior or attitude of their family members.

\subsection{Scale Reliabilities and Intercorrelations}

As indicated in Table 2, the reliability coefficients for all the measures were in the range of .74 for Resilience to .93 for Trust. Hurt intensity was a single item measure on a continuum from zero to 10. The subscales of Absence of Negative (reverse scored) and Presence of Positive were combined to get a total score for Forgiveness, which had a coefficient reliability of .90. In testing Hypothesis 2

Table 1. Frequencies and percentages of hurt intensity level.

\begin{tabular}{ccc}
\hline Hurt Intensity Level & Frequency & $\%$ \\
\hline 0 & 6 & 1.6 \\
1 & 19 & 9.0 \\
2 & 37 & 11.9 \\
3 & 45 & 13.3 \\
4 & 50 & 16.2 \\
5 & 61 & 17.0 \\
6 & 64 & 13.5 \\
7 & 51 & 8.2 \\
8 & 31 & 1.6 \\
9 & 6 & 1.9 \\
10 & 7 & 2 \\
\hline
\end{tabular}

$N=377$. 
Table 2. Reliability coefficients, means, standard deviations, and correlations.

\begin{tabular}{|c|c|c|c|c|c|c|c|c|c|c|c|c|c|c|}
\hline & & $\alpha$ & $M$ & $S D$ & 1 & 2 & 3 & 4 & 5 & 6 & 7 & 8 & 9 & 10 \\
\hline 1) & Gender & --- & --- & --- & -- & .02 & -.05 & $.17^{\star}$ & .08 & $-.18^{\star}$ & $.12^{\#}$ & .08 & .09 & $.11^{\wedge}$ \\
\hline 2) & Optimism & .84 & 3.35 & .74 & & --- & $.65^{\star}$ & $.34^{\star}$ & $.39^{*}$ & $-.24^{\star}$ & $-.13^{\#}$ & $.27^{\star}$ & $.41^{*}$ & $.39^{*}$ \\
\hline 3) & Resilience & .74 & 3.22 & .74 & & & --- & $.25^{*}$ & $.28^{*}$ & $-.11^{\star}$ & -.03 & $.12^{*}$ & $.31^{*}$ & $.24^{*}$ \\
\hline 4) & Trust & .93 & 3.68 & .90 & & & & --- & $.79^{*}$ & $-.50^{*}$ & $-.29^{*}$ & $.56^{\star}$ & $.53^{*}$ & $.63^{*}$ \\
\hline 5) & Communication & .92 & 3.41 & .89 & & & & & --- & $-.40^{*}$ & $-.33^{*}$ & $.45^{\star}$ & $.45^{*}$ & $.52^{*}$ \\
\hline 6) & Alienation & .87 & 2.31 & .89 & & & & & & --- & $.24^{\star}$ & $-.65^{\star}$ & $-.36^{\star}$ & $-.61^{\star}$ \\
\hline 7) & Hurt Intensity & --- & 4.90 & 2.21 & & & & & & & --- & $-.47^{\star}$ & $-.26^{*}$ & $-.44^{*}$ \\
\hline 8) & Absence of Negative & .91 & 3.75 & .83 & & & & & & & & --- & $.47^{*}$ & $.81^{\star}$ \\
\hline 9) & Presence of Positive & .84 & 3.36 & .73 & & & & & & & & & --- & $.89^{*}$ \\
\hline & Forgiveness & .90 & 3.57 & .67 & & & & & & & & & & --- \\
\hline
\end{tabular}

$N=377 ;{ }^{*} p<.001 ;{ }^{*} p<.01 ;{ }^{\wedge} p<.05 ;$ two-tailed.

and on inspection of the correlational matrix as presented in Table 2, out of 45 possible correlations, 39 of them were significant. As per Cohen's (1988) criteria (small effect, $r=.10$ to .29 ; medium effect, $r=.30$ to .49 , and large effect, $r=.50$ to 1.0 ), most of the significant correlations were in the medium effect range and 11 significant correlations were in the large effect range.

In addition to the strongest positive correlation of the two subscales with the total forgiveness scale, the next strongest positive correlation was between trust and communication, $r(377)=.79, p<.001$, suggesting that these two relationship variables vary together. The other strong positive correlation was between optimism and resilience, $r(377)=.65, p<.001$, suggesting that these two positive dispositional traits mutually influence each other, with high disposition in one being associated with high disposition in the other. The relationship variable of alienation had a strong negative correlation with forgiveness, $r(377)=-.61, p$ $<.001$, suggesting that alienation in family relationships is associated with lower attitudes and behaviors of forgiveness.

\subsection{Multiple Regression Analyses}

To test Hypothesis 3, we conducted hierarchical multiple regression to assess the ability of gender, positive dispositional tendencies, relationship variables, and hurt intensity to predict forgiveness. The results are presented in Table 3. We entered gender in Step 1 and it explained only $1 \%$ of the variance in forgiveness, $F(1,375)=4.55, p<.05, R^{2}=.01$. After we entered the positive dispositional tendencies of optimism and resilience in Step 2, the model explained $17 \%$ of variance, i.e., the dispositional tendencies together explained an additional 16\% of variance in forgiveness, after controlling for gender. Optimism, $\beta=.41, p<.001$, emerged as a sole predictor in Step 2. Resilience was not significant as a predictor of forgiveness. We entered three family relationship variables in Step 3, and the whole model explained $54 \%$ of variance in forgiveness, $F(6,370)=71.35$, 
Table 3. Summary of hierarchical regression analyses for variables predicting forgiveness.

\begin{tabular}{|c|c|c|c|c|c|c|c|c|c|c|c|c|}
\hline & \multicolumn{3}{|c|}{ Model 1} & \multicolumn{3}{|c|}{ Model 2} & \multicolumn{3}{|c|}{ Model 3} & \multicolumn{3}{|c|}{ Model 4} \\
\hline & $B$ & $S E$ & $\beta$ & $B$ & $S E$ & $\beta$ & $B$ & $S E$ & $\beta$ & $B$ & $S E$ & $\beta$ \\
\hline Gender & .15 & .07 & $.11^{\#}$ & .16 & .07 & $.12^{\#}$ & .02 & .05 & .02 & .04 & .05 & .03 \\
\hline Optimism & & & & .37 & .06 & $.41^{*}$ & .15 & .04 & $.17^{*}$ & .15 & .04 & $.16^{*}$ \\
\hline Resilience & & & & .02 & .06 & .02 & .02 & .04 & .01 & .01 & .04 & .01 \\
\hline Trust & & & & & & & .29 & .05 & $.37^{*}$ & .28 & .04 & $.37^{\star}$ \\
\hline Communication & & & & & & & .01 & .05 & .01 & -.05 & .04 & -.06 \\
\hline Alienation & & & & & & & -.29 & .03 & $-.37^{\star}$ & -.26 & .03 & $-.34^{*}$ \\
\hline Hurt Intensity & & & & & & & & & & -.08 & .01 & $-.26^{*}$ \\
\hline$R^{2}$ & & .01 & & & .17 & & & .54 & & & .59 & \\
\hline$F$ & & $4.55^{\#}$ & & & $24.71^{\star}$ & & & $71.35^{*}$ & & & $76.34^{\star}$ & \\
\hline$d f$ & & $1: 375$ & & & $3: 373$ & & & $6: 370$ & & & $7: 369$ & \\
\hline
\end{tabular}

$N=377 ;{ }^{*} p<.001 ;{ }^{*} p<.05$.

$p<.001, R^{2}=.54$. That is, the relationship variables together explained an additional $37 \%$ of variance in forgiveness, after controlling for both gender (Step 1) and positive dispositional tendencies (Step 2). The inspection of the contribution of the individual predictor variables in Step 3 indicated that communication was not significant, whereas both trust, $\beta=.37, p<.001$, and alienation, $\beta=-.37, p$ $<.001$, were significant.

In the final step, hurt intensity was significant and explained additional 5\% of variance in forgiveness, over and above the variance explained by the family relationship variables, $F(7,369)=76.34, p<.001, R^{2}=.59 ; \beta=-.26, p<.001$. These significant results suggest that after controlling for both demographic variables such as gender and dispositional variables such as traits, the family relationship variables along with the intensity of the hurt experienced by the victim in the context of family offenses play a significant role in predicting the levels of forgiveness of the family offender.

\section{Discussion}

\subsection{Family Relationship between the Victim and the Offender}

When talking about forgiveness in the context of families, the first question that comes to anyone's mind is about the relationship between the victim and the offender. In this study, the almost similar percentages of student participants indicated that the father, mother, and siblings equally offended them. Specifically, the results were distributed in the proportion of 128 (34\%) for sibling as the offender, 127 (33.7\%) for father, and 122 (32.4\%) for mother.

Given the age and developmental stage of these college students, it appears to be necessary that the parents are involved more than the other family members in the life of the college students, consequently leading to the chances of more 
interpersonal transgressions. Indeed, research has indicated that the majority of young adults entering college traverse this transitional stage accompanied by their parents (Fingerman, Cheng, Tighe, Birditt, \& Zarit, 2012; Gavazzi, 2012; Schwanz, Palm, Hill-Chapman, \& Broughton, 2014).

A study by Mao, Hsu, and Fang (2016) on the exploration of the Taiwanese university student perceptions of parental support concluded that parental support includes four themes: autonomy support, tangible assistance, emotional support, and information support. Mao and colleagues also indicated autonomy support as the most difficult for Taiwanese parents to provide to their college-going children. They further said that when there is a conflict between the development of personal interest of college students and parental expectations, students usually use four different coping styles: protest, avoidance, struggle, and submission. These categories of Taiwanese students' coping styles, except submission, in the midst of conflict with their parents indicate a higher chance of interpersonal transgressions in their family relationships and the need for conflict resolution through forgiveness.

\subsection{Nature of Transgressions in Taiwanese Families}

Given the long-term nature of family ties and the intensity of the interactions, family conflicts resulting in hurt and the need for resolution and forgiveness occur regularly in family settings. It appears self-evident that motivation and ability to forgive depend on the nature and hurt intensity or severity of the transgressions, which include physical abuse, emotional blackmail, insult or revelation of secrets.

Participants in this study thought that being compared with others by a family member was the third most occurring offensive behavior. In fact, participants chose this behavior as the most serious offense committed by the family member. The Chinese families usually think that their children's overall performance and particularly their personal academic achievement is the value and honor of the whole family (Chao, 2001). The literature on parenting styles suggests that the authoritarian parents attempt to control their children with absolute standards, and expect obedience and respect for authority from their children. In contrast, authoritative parents expect mature behavior from their children, set clear standards and enforce them firmly, encourage independence and individuality, engage in an open communication, and recognize the rights of their children. The literature has also suggested that parents of Chinese ethnicity with their respect for Confucian values are higher in general authoritarianism. In response to poor performance of their children, the authoritarian parents get upset and show it by means of comparison. Even if their children perform to their maximum potential, the parents tend to tell their children to do even better (Leung, Lau, \& Lam, 1998). Thus, it appears that it is a general understanding that comparison by Taiwanese parents is a common approach to ascertain the performance of their children. Parents compare their children's performance 
with others and then determine whether their achievements are normal, better or excellent. But, when comparisons by parents of their children with others are overdone or involve unrealistic expectations and negative attitudes, they produce negative effects.

The participants felt that contempt was another transgression that occurred most often in Taiwanese families, and it was also the second most serious offense as per the participants' experiences of family interpersonal transgressions. The choice for contempt seems to logically follow the most serious offense of being compared with others, because contempt is a feeling that a person is worthless or beneath consideration. Fischer and Roseman (2007) said that the social function of contempt is perhaps done because the person who is feeling contempt perceives that there is no way to influence or change the other person, or changing another person's behavior is not worth the effort, which results in ignoring the person. In other words, contempt sends messages that elicit psychological hurt. Vangelisti (1994) argued that a few ill-intended or ill-spoken words, such as "you are worthless" or "you will never amount to anything," can strongly affect interpersonal interactions and relationships.

\subsection{Intensity of the Hurt Experienced by the Victim}

Over $50 \%$ of the participants experienced moderate to above the average levels of hurt intensity. Lemay, Overall, and Clark (2012) said that hurt occurs when the victim perceives and feels rejection or devaluation by a perpetrator who is highly valued by the victim. As the nature of the most serious offenses and the relation to the perpetrator in this study indicated, both the transgressions of being compared with others and experiencing contempt appear to be the cause of perception and feeling of devalued by the highly valued family members, i.e. parents and siblings.

Higher levels of hurt intensity felt by the participants also imply that the offended in a family context is vulnerable to psychological pain at the hands of the close family offender, and this vulnerability is likely due to the offended member's desire for a relationship with the offender. In fact, several studies have proposed that the victim's dependence on the perpetrator for support, security, and protection creates the potential to feel hurt by relational devaluation (see Lemay, et al., 2012; Shaver, Mikulincer, Lavy, \& Cassidy, 2009). Moreover, if the parental involvement and support may not end when students enter college and young adulthood (Fingerman, et al., 2012; Schwanz, et al., 2014), and if dependence is a central component of feeling hurt in response to relational devaluation (Lemay, et al., 2012), the offended who highly value the family relationships and are committed to them should be more likely to feel hurt in these contexts. In general and as the results of this study have indicated, it is painful when our family members hurt us, because we are tied to one another involuntarily and we hold firm beliefs that our family members will be there for us unconditionally. Therefore, naturally, when someone that we are so closely related to says or does 
something to hurt us, we perceive it as worse than when someone that we are less related to does or says the same thing.

\subsection{Relations among the Major Study Variables}

The results indicated a strong significant correlation between optimism and resilience. Optimism is an individual trait that reflects the extent to which people hold generalized favorable expectancies for their future (Walsh, 2003). As the past studies have indicated (see Carver, Scheier, \& Segerstrom, 2010; Rutter, 2006), the characteristic of resilience for this sample reflects their desire for great optimism under the adversity of family offences and transgressions. There was also a positive correlation between optimism and forgiveness, implying that participants who displayed more optimism were more likely to forgive their offenders. Optimism helps the offended to make a decision to forgive the offender in order to have and maintain happy, healthy, and positive relationships. Because optimism sets the path for a better future, the offended is able to find the positives in forgiving the offender.

The significant positive relationship between higher levels of resiliency correspond to higher levels of forgiveness, and conversely, lower levels of resiliency correspond to lower levels of forgiveness. Flach (1988) contends that resiliency is a strength that humans require to master cycles of disruption and reintegration throughout the life cycle. In this study, the positive significant correlation between resiliency and forgiveness implies that the resilient participants possess the capacity to forgive as they are able to understand that something good can come out of even the hurtful offenses in involuntary interpersonal relationships occurring in the context of families.

As expected, the relationship variables of trust and communication were significantly and highly correlated. Communication is described as the formal as well as the informal sharing of meaningful information. Trust is defined as an expectancy held by an individual or a group that the verbal or written word or promise of another individual or a group can be relied upon (Zeffane, Tipi, \& Ryan, 2011). Trust is an important pillar in any kind of relationships. Building trust fosters healthy communication among family and friends, and healthy and open communication in relationships opens the pathways for trust to develop in useful ways. There was also a positive significant correlation between trust and forgiveness, implying that highly trusting individuals are more likely to forgive their offenders. The positive correlation between communication and forgiveness implies that the process of forgiveness involves positive communication (Sheldon, Gilchrist-Petty, \& Lessley, 2014).

Alienation in relationships and the feeling of hurt by the family offenses were positively correlated, whereas alienation and forgiveness were negatively correlated. Research (see Scharp \& Hall, 2017) has shown that despite the well accepted assumptions that families are close and intact, the prevalence of alienation, marginalization, and estrangement of family member is overwhelming. 
These processes pose significant disruptions to the entire family system. Vangelisti (2006) explains that the involuntary nature of family relationships places tight constraints on the member's relational alternatives. When family members are happy and well-adjusted, these constraints may increase members' commitment to the family as a whole, but when family members are offended or abused, distressed or psychologically troubled, the same restrictions may place them at a great deal of hurt.

\subsection{Incremental Predictors of Forgiveness in Families}

All the step-wise regression models were significant in predicting forgiveness. After controlling for the effects of gender on forgiveness in Step 1, the positive dispositional tendencies of optimism and resilience together significantly increased the variance in forgiveness in Step 2. But only optimism, defined as generalized expectancies for desirable future outcomes (Carver, et al., 2010), significantly predicted forgiveness of family member's transgression. Research confirms that individuals who are disposed to hold positive expectations for the future respond to any sort of adversity in more adaptive ways (Rey \& Extremera, 2014). In the case of forgiveness in interpersonal relationships, Worthington and Wade (1999) have stated that an optimistic view of a relationship and oneself in that relationship is expected to influence the occurrence of forgiveness. The positive dispositional quality of resilience was not significant.

In Step 3, trust significantly contributed to the variance in forgiveness. The ability to trust and maintain healthy relationships was a recurring theme in forgiveness studies (see Asendorpf \& Wilpers, 1998; Boon \& Sulsky, 1997; McCullough, Worthington, \& Rachael, 1997). Studies indicated that of the many aspects of relationships that could contribute to forgiveness dynamics, trust that relationship partners place in one another is one quality that has been widely researched (see Finkel et al., 2002; McCullough et al., 1998). Rousseau, Sitkin, Burt, and Camerer (1998) noted that trust essentially entails an acceptance of vulnerability based upon positive expectations of the intentions of another. From this perspective, trust could potentially motivate forgiveness in one of two ways. It could increase perceptions of safety from the possibility of future offenses. Or, it could increase perceptions of opportunities for future benefits from a relationship. In other words, following an offense by a relationship partner, those who trust their partner typically form more benevolent (ren) interpretations of the offense, and retain more positive evaluations of the offender (guan-xi), leading to higher likelihood of granting forgiveness.

Moreover, one of the cardinal virtues of Confucianism is trust (xin), which is interpreted as the state of mind that is without deception or lies when relating to others. In one's family and social life, if one is to have a meaningful relationship with others, one should be trustworthy, without cheating or lying (Zhang, 2002). Thus, xin is directly correlated with positive relationships, and vice versa. One significant feature of xin, suggested by the Chinese character itself, indicates that it is comprised of ren (person) and yan (speech or language), suggesting that the 
person with xin or the trustworthy person is the one who does what he/she has said would do (Wee, 2011). Thus, xin means trustworthiness in word or verbal commitment, and when it is applied to the interpersonal relationships in family context, it leads to forgiveness in the context of family transgressions. That is, as Wee (2011) indicated, one can say that the person of xin is sincere in his/her attempts to ensure that others can rely on him/her and he/she may be said to be generally well-disposed toward others. Therefore, in the context of this study, when the victim perceives the family offender as trustworthy to an extent that the offender is said to be well-disposed toward the victim, there is said to be a higher chance for forgiveness.

In Step 3, the relationship variable of alienation also significantly and inversely predicted forgiveness, implying that the participants who feel alienated and distance in the family are less likely to forgive their offenders. Richman and Leary (2009) said that all negative or offensive interpersonal attitudes or events have the potential to lower the victims' perceived relational value. Richman and Leary further said that a person who has been rejected may simultaneously wish to regain acceptance, retaliate against those who hurt him or her, and avoid further social contact. In the case of this sample, people who feel alienated or rejected appear to retaliate against those who offended them by not willing to forgive them. This aspect seems to echo Shun's (2014) interpretation of the concept of forgiveness in Chinese literature in which the forgiveness or unforgiveness might have to do with the change conveyed through being narrow-minded ( $b i)$ to being broad-minded (kuan). Here, the relationship variable of alienation appears to suggest that the victims in response to the offenses by the family member tend to be narrow-minded in working towards restoring a hurtful relationship.

In addition, the Confucian cardinal virtue of ren (benevolence), commonly translated as benevolence, represents the figure of two people, indicating that ren is thought to be possible only when one human being is in relationship with another and thus one cannot be ren by oneself. Alienation, in some sense, is the opposite of ren. Benevolence or ren is the characteristic element of humanity and it is greatly exercised in loving the family members and relatives. Confucius said that ren requires that we do not impose upon others what we do not want for ourselves (Park \& Chesla, 2007), which is forgiveness. But, alienation as the description of one cannot be ren by oneself, deprives an opportunity or a chance (ji-yuan) for the victim to extend benevolence and forgiveness toward the offender.

Finally, hurt intensity also negatively and significantly predicted forgiveness. Studies on the features of hurt feelings suggest that hurt is a distinct negative emotion that is associated with feeling devalued, unwanted, and rejected (Richman \& Leary, 2009). For this sample, it appears that feeling of more severely hurt by individuals who were perceived as being close to the transgressor were more likely not to forgive the offender. This result is supported by the literature that increased severity of offense and decreased closeness of victim-offender relationship as factors closely related to unforgiveness (Bono, McCullough, \& Root, 
2008; McCullough et al., 1998).

As a summary, it can be said that it is not only the set of personality dispositions that predicts whether one is inclined or not to forgive the family offender, but more importantly, it is the set of family relationship variables that further validates the prediction of forgiveness in the families. Additionally, as this study results have suggested, when the intensity of hurt caused by a specific offense by a close family member is included in the incremental validity analysis, it is indicated that beyond both the personality dispositions and family relationships, the intensity of hurt as subjectively felt or perceived by the offended significantly contributes to the forgiveness of the family offender.

\section{Implications, Limitations, and Future Directions}

The significant results of this quantitative research help us to understand the determinants of forgiveness of a family transgressor by the offended in a Taiwanese context. First of all, the results suggest that offense-specific analysis gives clearer understanding of the differences that exist due to geographical and cultural differences. Although the understanding of families has been changing in modern Taiwan, they still place a great emphasis on filial piety (xiao-shun) and relationships (guan-Xi). Investigating the specific offenses that the participants indicated in this research study suggests that there are some similar offenses with other cultures; offenses such as unequal treatment of siblings, inequitable distribution of household tasks, and instances of broken family commitments. Some of the offenses that seem to be typical to the Taiwanese family context are being ignored and being compared with others. These results warrant that understanding the process of forgiveness in families should take the cultural and ethnic aspects into consideration.

Participants indicated three conceptually inter-related offenses, i.e., being compared with others, contempt, and being ignored, as the most serious offenses. It could be due to the concept of face-saving (mian-zi) in the general Chinese culture. One of the serious things in distorting family reputation in Chinese culture is to "lose face" (diu-lian). Once again, these differences call for an understanding of the cultural importance of face in the process of dealing with family offenses and the operation of forgiveness in Taiwanese families.

The college students in this research study indicated that father, mother, and siblings equally offend them. This result is in line with the aforementioned most serious offenses and the concepts of filial piety (xiao-shun), relationships (guan-Xi), and face-saving (mian-zi). Moreover, both culturally and developmentally, it appears to be necessary that the parents are involved more in the life of the Taiwanese college students, consequently leading to the chances of frequent and specific interpersonal transgressions between parents and college-going children. In addition, the transgressions among the siblings seem to mostly occur due to the comparison and the sense of being ignored. Finally, the relationship variables along with the intensity of the hurt experienced by the victim in the context of family played a significant role in the forgiveness of the 
family offender. Regarding the positive dispositional traits, like the previous research has indicated, those individuals who are able to perceive positive expectations for the families tend to be more adaptable to family transgressions and more able to use the mechanism of forgiveness to resolve interpersonal problems in the context of families. But, when the relational variables of trust, communication, and alienation are entered into the regression equation, both demographic and dispositional variables became non-significant, once again suggesting that the relationship factors, including the hurt feelings that occur due interpersonal transgressions, play a significant role in the process of forgiveness in families.

Even though the findings from this research provide promising empirical evidence for the contribution of positive dispositional characteristics and relationship variables in relation to interpersonal forgiveness in the context of families, we should acknowledge some limitations of the study. One obvious limitation is the use of a cross-sectional quantitative design, which prevents us from drawing definitive causal inferences. Thus, it should be noted that the percentage of additional explained variance of hurt intensity in forgiveness, compared to relationship variables and positive dispositional characteristics, was very modest (explaining about $5 \%$ of the increment variance). Yet, this small effect should not be dismissed when the outcomes are important. Moreover, and in particular, the field of interpersonal forgiveness in any context is known to be quite broad and includes a large number of distal determinants (Riek \& Mania, 2012), in addition to intensity of the hurt, relationship variables and positive dispositional characteristics measured in this study. Therefore, including more relevant determinants in analysis may broaden the understanding of forgiveness in families. Also, qualitative research may be useful in understanding the individual process and experience of forgiveness in the context of family, in which the participants could be asked to mention a specific offense and then describe in a narrative form the process of forgiveness or lack of it.

Another limitation is the selection of a relatively young undergraduate student sample. Therefore, these results need to be replicated with older participants and those from community-based samples to help increase the confidence in current findings. A third limitation is that the assessment of forgiveness was based upon retrospective recall by the individual of a prior offense. A questionnaire item asking the participants to state how long ago the offense occurred would have been useful in accurately assessing the beliefs, thoughts, and feelings about the offender post-offense. Finally, although gender significantly correlated with forgiveness and predicted forgiveness, gender differences in forgiveness were not tested in this study. Many scholars assume that women usually are more forgiving than men. Investigating for gender differences and discussing why or why not they occur may be warranted in the future studies.

\section{Conclusions}

In this study, we tried to investigate the demographic, dispositional, and rela- 
tional determinants of forgiveness in Taiwanese families from the perspective of college students. In line with the previous research results, our study also attested to the reality that the frequency of offenses is higher and intensity of the hurt is deeper in the involuntary and more permanent family relationships. In addition, because family members share a biological connectedness that is not present in other social groups; usually are more intensely bonded through emotional ties, and often share a family world view, the process of forgiveness becomes an effective means by which to maintain family harmony and restore relationship following family transgressions. Consequently, the failure to forgive may result in deleterious effects, such as destructive conflict and disruption of the family relationships.

It is also necessary for the scholars in family studies in general and for those who study family forgiveness in particular to be aware of the complexity of defining the family and operationalizing the family forgiveness, as it is more often linked to changing and inescapable ideological differences, driven by history, culture, and situation. For example, as the results from this study have indicated, issues as to what counts as an offense, which family member is more often involved in the family offenses, what kind of offense causes intense hurt, what sort of dispositional tendencies and relationship variables play a role in the process of forgiveness, and so on, suggest that the family dynamics and relationships should be understood and investigated in the light of the changing ideological differences and varying cultural values.

\section{References}

Armsden, G. C., \& Greenberg, M. T. (1987). The Inventory of Parent and Peer Attachment: Individual Differences and Their Relationship to Psychological Well-Being in Adolescence. Journal of Youth and Adolescence, 16, 427-454.

https://doi.org/10.1007/BF02202939

Asendorpf, J. B., \& Wilpers, S. (1998). Personality Effects on Social Relationships. Journal of Personality and Social Psychology, 74, 1531-1544. https://doi.org/10.1037/0022-3514.74.6.1531

Back, M. D., \& Kenny, D. A. (2010). The Social Relations Model: How to Understand Dyadic Processes. Social and Personality Psychology Compass, 4, 855-870. https://doi.org/10.1111/j.1751-9004.2010.00303.x

Battle, C. L., \& Miller, I. W. (2005). Families and Forgiveness. In E. L. Worthington (Ed.), Handbook of Forgiveness (pp. 227-241). New York, NY: Routledge.

Beach, S. R. H., \& Whisman, M. (2012). Relationship Distress: Impact on Mental Illness, Physical Health, Children, and Family Economics. In S. R. H. Beach, R. Heyman, A. Smith, \& H. Foran (Eds.), Family Problems and Family Violence (pp. 91-100). New York, NY: Springer.

Bono, G., McCullough, M., \& Root, L. (2008). Forgiveness, Feeling Connected to Others, and Well-Being: Two Longitudinal Studies. Personality and Social Psychology Bulletin, 34, 182-195. https://doi.org/10.1177/0146167207310025

Boon, S. D., \& Sulsky, L. M. (1997). Attributions of Blame and Forgiveness in Romantic Relationships: A Policy-Capturing Study. Journal of Social Behavior and Personality, 12, 19-44. 
Brennan, A., \& Fan, R. (2007). Autonomy and Interdependence: A Dialogue between Liberalism and Confucianism. Journal of Social Philosophy, 38, 511-535. https://doi.org/10.1111/j.1467-9833.2007.00396.x

Brose, A., Rye, M., Lutz-Zois, C., \& Ross, S. R. (2005). Forgiveness and Personality Traits. Personality and Individual Differences, 39, 35-46. https://doi.org/10.1016/j.paid.2004.11.001

Campbell-Sills, L., \& Stein, M. B. (2007). Psychometric Analysis and Refinement of the Connor-Davidson Resilience Scale (CD-RISC): Validation of a 10-Item Measure of Resilience. Journal of Traumatic Stress, 20, 1019-1028. https://doi.org/10.1002/jts.20271

Carifio, J., \& Rhodes, L. (2002). Construct Validities and the Empirical Relationships between Optimism, Hope, Self-Efficacy, and Locus of Control. Work, 19, 125-136.

Carver, C. S., Scheier, M. F., \& Segerstrom, S. C. (2010). Optimism. Clinical Psychology Review, 30, 879-889.

Cavanagh, S. E., \& Huston, A. C. (2008). The Timing of Family Instability and Children's Social Development. Journal of Marriage and Family, 70, 1258-1269.

https://doi.org/10.1111/j.1741-3737.2008.00564.x

Chan, W. T. (1963). A Source Book in Chinese Philosophy. Princeton, NJ: Princeton University Press.

Chang, H. C., \& Holt, G. R. (1991). More than Relationship: Chinese Interaction and the Principle of Kuan-Hsi. Communication Quarterly, 39, 251-271. https://doi.org/10.1080/01463379109369802

Chao, R. K. (2001). Extending Research on the Consequences of Parenting Style for Chinese Americans and European Americans. Child Development, 72, 1832-1843. https://doi.org/10.1111/1467-8624.00381

Cohen, J. (1988). Statistical Power Analysis for Behavioral Sciences (2nd ed.). Hillsdale, NJ: Lawrence-Erlbaum.

Cotterell, N., Eisenberger, R., \& Speicher, H. (1992). Inhibiting Effects of Reciprocation Wariness on Interpersonal Relationships. Journal of Personality and Social Psychology, 62, 658-668. https://doi.org/10.1037/0022-3514.62.4.658

DeBlasio, F. A. (1998). The Use of a Decision-Based Forgiveness Intervention within Intergenerational Family Therapy. Journal of Family Therapy, 20, 77-94.

Enright, R. D., Freedman, S. R., \& Rique, J. (1998). The Psychology of Interpersonal Forgiveness. In R. D. Enright, \& J. North (Eds.), Exploring Forgiveness (pp. 46-62). Madison, WI: University of Wisconsin Press.

Family (2017). Taiwanese Culture.

https://culturalatlas.sbs.com.au/taiwanese-culture/family-9a72fb03-04d5-4107-9a17-e9 08795b983e

Fan, R. (2002). Reconsidering Surrogate Decision-Making: Aristotelianism and Confucianism on Ideal Human Relations. Philosophy East \& West, 52, 346-372. https://doi.org/10.1353/pew.2002.0013

Fincham, F. D. (2000). The Kiss of the Porcupines: From Attributing Responsibility to Forgiving. Personal Relationships, 7, 1-23. https://doi.org/10.1111/j.1475-6811.2000.tb00001.x

Fincham, F. D. (2015). Forgiveness, Family Relationships and Health. In L. L. Toussaint, E. L. Worthington Jr., \& D. R. Williams (Eds.), Forgiveness and Health: Scientific Evidence and Theories Relating Forgiveness to Better Health (pp. 255-269). New York, NY: Springer. https://doi.org/10.1007/978-94-017-9993-5_17

Fincham, F. D., Hall, J., \& Beach, S. R. H. (2006). Forgiveness in Marriage: Current Status 
and Future Directions. Family Relations, 55, 415-427. https://doi.org/10.1111/j.1741-3729.2005.callf.x-i1

Fincham, F. D., Harold, G. T., \& Gano-Phillips, S. (2000). The Longitudinal Association between Attributions and Marital Satisfaction: Direction of Effects and Role of Efficacy Expectations. Journal of Family Psychology, 14, 267-285. https://doi.org/10.1037/0893-3200.14.2.267

Fincham, H. D., Jackson, H., \& Beach, S. R. H. (2005). Transgression Severity and Forgiveness: Different Moderators for Objective and Subjective Severity. Journal of Social and Clinical Psychology, 24, 860-875. https://doi.org/10.1521/jscp.2005.24.6.860

Fingerman, K. L., Cheng, Y. P., Tighe, L., Birditt, K. S., \& Zarit, S. (2012). Relationships between Young Adults and Their Parents. In A. Booth, S. L. Brown, N. S. Landale, W. D. Manning, \& S. M. McHale (Eds.), Early Adulthood in a Family Context (pp. 59-85). New York, NY: Springer-Verlag. https://doi.org/10.1007/978-1-4614-1436-0_5

Finkel, E. J., Rusbult, C. E., Kumashiro, M., \& Hannon, P. A. (2002). Dealing with Betrayal in Close Relationships: Does Commitment Promote Forgiveness? Journal of Personality and Social Psychology, 82, 956-974. https://doi.org/10.1037/0022-3514.82.6.956

Fischer, A. H., \& Roseman, I. J. (2007). Beat Them or Ban Them: The Characteristics and Social Functions of Anger and Contempt. Journal of Personality and Social Psychology, 93, 103-115. https://doi.org/10.1037/0022-3514.93.1.103

Flach, F. (1988). Resilience: Discovering a New Strength at Times of Stress. New York, NY: Fawcett Columbine.

Gavazzi, S. M. (2012). Renegotiating Relationships between Parents and College Students. NCFR Online Digital Archive.

https://archive.ncfr.org/ncfr-community-blog/renegotiating-relationships-between-par ents-and-college-students

Haynes, S. N., \& Lench, H. C. (2003). Incremental Validity of New Clinical Assessment Measures. Psychological Assessment, 69, 456-466. https://doi.org/10.1037/1040-3590.15.4.456

Hoyt, W. T., Fincham, F. D., McCullough, M. E., Maio, G., \& Davila, J. (2005). Responses to Interpersonal Transgressions in Families: Forgivingness, Forgivability, and Relationship-Specific Effects. Journal of Personality and Social Psychology, 89, 375-394. https://doi.org/10.1037/0022-3514.89.3.375

Huang, G. H. C., \& Gove, M. (2012). Confucianism and Chinese Families: Values and Practices in Education. International Journal of Humanities and Social Science, 2, $10-14$.

Kaminer, D., Stein, D. J., Mbanga, I., \& Zungu-Dirwayi, N. (2000). Forgiveness: Toward an Integration of Theoretical Models. Psychiatry, 63, 344-357. https://doi.org/10.1080/00332747.2000.11024928

Karremans, J. C., \& Van Lange, P. A. M. (2004). Back to Caring after Being Hurt: The Role of Forgiveness. European Journal of Social Psychology, 34, 207-227. https://doi.org/10.1002/ejsp.192

Karremans, J. C., Van Lange, P. A. M., Ouwerkerk, J. W., \& Kluwer, E. S. (2003). When Forgiving Enhances Psychological Well-Being: The Role of Interpersonal Commitment. Journal of Personality and Social Psychology, 84, 1011-1026. https://doi.org/10.1037/0022-3514.84.5.1011

Lemay, E. P., Overall, N. C., \& Clark, M. S. (2012). Experiences and Interpersonal Consequences of Hurt Feelings and Anger. Journal of Personality and Social Psychology, 103, 982-1006. https://doi.org/10.1037/a0030064 
Leung, K., Lau, S., \& Lam, W. L. (1998). Parenting Styles and Academic Achievement: A Cross-Cultural Study. Merrill-Palmer Quarterly, 44, 157-172.

Lu, L., \& Shih, J. B. (1997). Sources of Happiness: A Qualitative Approach. The Journal of Social Psychology, 137, 181-187. https://doi.org/10.1080/00224549709595429

Maio, G. R., Thomas, G., Fincham, F. D., \& Carnelley, K. (2008). Unraveling the Role of Forgiveness in Family Relationships. Journal of Personality and Social Psychology, 94, 307-319. https://doi.org/10.1037/0022-3514.94.2.307

Mao, C. H., Hsu, Y. C., \& Fang, T. W. (2016). Parental Support as Perceived by Taiwanese University Students during Career Development. International Journal of Psychology and Behavioral Sciences, 6, 63-70.

Markey, P. M., Funder, D. C., \& Ozer, D. J. (2003). Complementarity of Interpersonal Behaviors in Dyadic Interactions. Personality and Social Psychology Bulletin, 29, 1082-1090. https://doi.org/10.1177/0146167203253474

McCullough, M. E., Fincham, F. D., \& Tsang, J. A. (2003). Trajectories of Forgiveness: The Temporal Unfolding of Transgression-Related Interpersonal Motivations. Journal of Personality and Social Psychology, 84, 540-557. https://doi.org/10.1037/0022-3514.84.3.540

McCullough, M. E., Hoyt, W. T., \& Rachal, K. C. (2000). What We Know (and Need to Know) about Assessing Forgiveness Constructs. In M. McCullough, K. I. Pargament, \& C. E. Thoresen (Eds.), Forgiveness: Theory, Research and Practice (pp. 65-90). New York, NY: Guilford.

McCullough, M. E., Rachal, K. C., Sandage, S. J., Worthington, E. L., Brown, S. W., \& Hight, T. L. (1998). Interpersonal Forgiving in Close Relationships: II. Theoretical Elaboration and Measurement. Journal of Personality and Social Psychology, 75, 1586-1603. https://doi.org/10.1037/0022-3514.75.6.1586

McCullough, M. E., Worthington, E. L., \& Rachael, K. C. (1997). Interpersonal Forgiving in Close Relationships. Journal of Personality and Social Psychology, 73, 321-336. https://doi.org/10.1037/0022-3514.73.2.321

Mooney, L., Strelan, P., \& McKee, I. (2015). How Forgiveness Promotes Offender Pro-Relational Intentions: The Mediating Role of Offender Gratitude. British Journal of Social Psychology, 55, 44-64. https://doi.org/10.1111/bjso.12120

Mullet, E., \& Girard, M. (2000). Developmental and Cognitive Points of View on Forgiveness. In M. E. McCullough, \& K. I. Pargament (Eds.), Forgiveness: Theory, Research, and Practice (pp. 111-132). New York, NY: Guilford Press.

North, J. (1987). Wrongdoing and Forgiveness. Philosophy, 62, 336-352. https://doi.org/10.1017/S003181910003905X

Nuyen, A. T. (2004). The Contemporary Relevance of the Confucian Idea of Filial Piety. Journal of Chinese Philosophy, 31, 433-450. https://doi.org/10.1111/j.1540-6253.2004.00164.x

Paleari, F. G., Regalia, C., \& Fincham, F. D. (2003). Adolescents' Willingness to Forgive Parents: An Empirical Model. Parenting: Science and Practice, 3, 155-174. https://doi.org/10.1207/S15327922PAR0302_03

Paleari, F. G., Regalia, C., \& Fincham, F. D. (2009). Measuring Offence-Specific Forgiveness in Marriage: The Marital Offence-Specific Forgiveness Scale. Psychological Assessment, 21, 194-209. https://doi.org/10.1037/a0016068

Park, M., \& Chesla, C. (2007). Revisiting Confucianism as a Conceptual Framework for Asian Family Study. Journal of Family Nursing, 13, 293-311.

https://doi.org/10.1177/1074840707304400 
Rey, L., \& Extremera, N. (2014). Positive Psychological Characteristics and Interpersonal Forgiveness: Identifying the Unique Contribution of Emotional Intelligence Abilities, Big Five Traits, Gratitude and Optimism. Personality and Individual Differences, 68, 199-204. https://doi.org/10.1016/j.paid.2014.04.030

Richman, L. S., \& Leary, M. R. (2009). Reactions to Discrimination, Stigmatization, Ostracism, and Other Forms of Interpersonal Rejection: A Multimotive Model. Psychological Review, 116, 365-383. https://doi.org/10.1037/a0015250

Riek, B. M., \& Mania, E. W. (2012). The Antecedents and Consequences of Interpersonal Forgiveness: A Meta-Analytic Review. Personal Relationships, 19, 304-325. https://doi.org/10.1111/j.1475-6811.2011.01363.x

Rousseau, D. M., Sitkin, S. B., Burt, R. S., \& Camerer, C. (1998). Not So Different after All: A Cross-Discipline View of Trust. The Academy of Management Review, 23, 393-404. https://doi.org/10.5465/amr.1998.926617

Rusbult, C. E., \& Van Lange, P. A. M. (2003). Interdependence, Interaction, and Relationships. Annual Review of Psychology, 54, 351-375. https://doi.org/10.1146/annurev.psych.54.101601.145059

Rutter, M. (2006). Implications of Resilience Concepts for Scientific Understanding. Annals of the New York Academy of Sciences, 1094, 1-12. https://doi.org/10.1196/annals.1376.002

Rye, M. S., Loiacono, D. M., Folck, C. D., Olszewski, B. T., Heim, T. A., \& Madia, B. P. (2001). Evaluation of the Psychometric Properties of Two Forgiveness Scales. Current Psychology, 20, 260-277. https://doi.org/10.1007/s12144-001-1011-6

Scharp, K. M., \& Hall, E. D. (2017). Family Marginalization, Alienation and Estrangement in Family Relationships: Questioning the Nonvoluntary Status of Family Relationships. Annals of the International Communication Association, 41, 28-45. https://doi.org/10.1080/23808985.2017.1285680

Schwanz, K. A., Palm, L. J., Hill-Chapman, C. R., \& Broughton, S. F. (2014). College Students' Perceptions of Relations with Parents and Academic Performance. American Journal of Educational Research, 2, 13-17. https://doi.org/10.12691/education-2-1-3

Sechrest, L. (1963). Incremental Validity: A Recommendation. Educational and Psychological Measurement, 23, 153-158. https://doi.org/10.1177/001316446302300113

Shaver, P. R., Mikulincer, M., Lavy, S., \& Cassidy, J. (2009). Understanding and Altering Hurt Feelings: An Attachment-Theoretical Perspective on the Generation and Regulation of Emotions. In A. Vangelisti (Ed.), Feeling Hurt in Close Relationships (pp. 92-120). New York, NY: Cambridge University Press. https://doi.org/10.1017/CBO9780511770548.007

Sheldon, P., Gilchrist-Petty, E., \& Lessley, J. A. (2014). You Did What? The Relationship between Forgiveness Tendency, Communication of Forgiveness, and Relationship Satisfaction in Married and dating Couples. Communication Patterns, 27, 78-90.

Shun, K. L. (2014). Resentment and Forgiveness in Confucian Thought. Journal of East-West thought, 4, 13-35.

Symington, S. H., Walker, D. F., \& Gorsuch, R. L. (2002). The Relationship of Forgiveness and Reconciliation to Five and Sixteen Factors of Personality. Journal of Psychology and Spirituality, 21, 141-150.

Takaku, S., Weiner, B., \& Ohbuchi, K. I. (2001). A Cross-Cultural Examination of the Effects of Apology and Perspective Taking on Forgiveness. Journal of Language and Social Psychology, 20, 144-166. https://doi.org/10.1177/0261927X01020001007

Vangelisti, A. (2006). Foreword: Family Communication Theories: Variations and Chal- 
lenges. In D. O. Braithwaite, \& L. A. Baxter (Eds.), Engaging Theories in Family Communication: Multiple Perspectives (pp. 9-18). Thousand Oaks, CA: Sage.

Vangelisti, A. L. (1994). Messages That Hurt. In W. R. Cupach, \& B. H. Spitzberg (Eds.), The Dark Side of Interpersonal Communication (pp. 53-82). Hillsdale, NJ: Lawrence Erlbaum Associates, Inc.

Wade, N. G., \& Worthington, E. L. (2003). Overcoming Interpersonal Offenses: Is Forgiveness the Only Way to Deal with Unforgiveness? Journal of Counseling \& Development, 81, 343-353. https://doi.org/10.1002/j.1556-6678.2003.tb00261.x

Walsh, F. (2003). Family Resilience: A Framework for Clinical Practice. Family Process, 42, 1-18. https://doi.org/10.1111/j.1545-5300.2003.00001.x

Wee, C. (2011). Xin, Trust, and Confucius' Ethics. Philosophy East and West, 61, 516-533. https://doi.org/10.1353/pew.2011.0047

Wieselquist, J., Rusbult, C. E., Foster, C. A., \& Agnew, C. R. (1999). Commitment, Pro-Relationship Behavior, and Trust in Close Relationships. Journal of Personality and Social Psychology, 77, 942-966. https://doi.org/10.1037/0022-3514.77.5.942

Worthington, E. L. (2001). Five Steps to Forgiveness: The Art and Science of Forgiving. New York, NY: Crown.

Worthington, E. L. (2005). More Questions about Forgiveness: Research Agenda for 2005-2015. In E. L. Worthington (Ed.), Handbook of Forgiveness (pp. 557-575). New York, NY: Routledge.

Worthington, E. L., \& Wade, N. G. (1999). The Psychology of Unforgiveness and Forgiveness and Implications for Clinical Practice. Journal of Social and Clinical Psychology, 18, 385-418. https://doi.org/10.1521/jscp.1999.18.4.385

Yang, C., \& Chen, J. (2016). Parent-Child Attachment, Self-Efficacy and Peer Relationships. Paper Presented at the Conference of Child and Family in Community, New Taipei City.

Zeffane, R., Tipu, S. A., \& Ryan, J. C. (2011). Communication, Commitment and Trust: Exploring the Triad. International Journal of Business and Management, 6, 77-87. https://doi.org/10.5539/ijbm.v6n6p77

Zhang, D. (2002). Key Concepts in Chinese Philosophy (E. Ryden, Trans.). New Haven, CT: Yale University Press. 